\title{
Shifted Laser Surface Texturing (sLST) in Burst Regime
}

\author{
Denys Moskal, Jiri Martan, Martin Kucera \\ New Technologies Research Centre (NTC), University of West Bohemia, \\ Univerzitni 8, 30100 Plzen, Czech Republic \\ E-mail:moskal@ntc.zcu.cz
}

\begin{abstract}
High laser-scanning speed and high precision are two opposite parameters for effective laser surface texturing (LST). Application of a sequence of laser pulses (called burst) helps to increase the processing effectivennes and speed, but precision control of laser pulses arriving becomes a difficult task for micro-texturing. In this work, one possible solution for this dilemma is presented: a scanning strategy called shifted laser surface texturing (sLST) in burst regime. This burst sLST represents an alternative method, where the inertia of galvanoscan mirrors becomes a useful factor at higher speeds. Physical principles of laser burst interaction with a material surface and resulting subsurface thermal-stress fields are discussed. Heat accumulation was calculated from a semi-planar model of temperature distribution from laser spots in the line of the burst. Residual subsurface temperature and pressure is called positive heat accumulation in the case of minimal output roughness of laser-scanned surfaces. Experimental application of the burst sLST was performed with a picosecond laser with a galvanoscan system. Results were evaluated by newly developed shape analysis of objects detected on contrast images of laser-processed stainless steel surfaces painted with highemissivity paint. Deviation in sLST precision was determined from larger and smaller diameters of detected microobjects on the surface with LabIR coating. The roughness of depth structure in microobjects was controlled by a contact surface profiler and compared with the goal profile and positive heat accumulation distribution. The sLST method in burst regime enables a significant increase of processing speed while maintaining good precision of the produced texture.
\end{abstract}

DOI: $10.2961 / \mathrm{jlmn} .2019 .02 .0011$

Keywords: laser surface texturing, burst regime, positive heat accumulation, scanning strategy, shifted LST

\section{Introduction}

Laser pulse interaction with material initiates a lot of physical processes - from appearance of a plasma plume to surface ablation and activation of thermomechanical stresses in subsurface layers [1-5]. In applications with a multipulse regime of material processing it is necessary to take into account some additional limitations, like plasma shielding or heat accumulation [6-10]. A plasma explosion has a great speed, up to $10 \mathrm{~km} / \mathrm{s}$ and its density reduces in hundreds of nanoseconds $[1,11]$. Heat accumulation appears from residual heat collected from the consequence of laser pulses and it has a longer influencing time, till several microseconds [12, 13]. Secondary laser ablation effects, such as shielding of the surface by laser ablated particles and thermal-activated surface oxidation take place at a later time and they are able to initiate more long-term consequences [1, 12]. From this point of view, application of a sequence of laser pulses with microsecond intervals or burst has its own benefits. Correct selection of delay between laser pulses and spot distance can increase the effectiveness of the laser material processing and give low roughness of the output surface at higher speeds [14-18]. However, laser pulse precision positioning at a higher speed of laser beam movement becomes a difficult task, especially in the case of microtexturing [19-21].
There are several techniques for precision control of the laser pulse arriving in synchronization with a scanning system. These include "pulse on demand" or "free trigger" techniques [22-24]. In any case, in a scheme with a synchronization loop between the scanning system and the laser pulse generator, it is necessary to spend technical time for communication to correct the processing of every object in laser surface texturing (LST). As a result, it is difficult to benefit from both: application of the laser pulse sequence at the higher scanning speed and high precision of scanning system.

An alternative solution was developed, called shifted laser surface texturing (sLST) in burst regime. It is described and discussed in this paper. This method enables a significant increase of processing speed with the same precision, which moves laser texturing towards wide industrial applicability.

\section{Method of sLST in burst regime}

Generally, LST for industrial applications requires equidistant laser formation of microobjects as holes, columns or some exotic structures - triangles or donuts [25$31]$. In the case of microtexturing by classical methods, the fastest method for surface processing will be hatching through all objects [32]. But in this case it is necessary to spend additional time for setting of the mirror position in 
accordance with laser pulses generation for every microobject. This can be explained on an example of the formation of a microdimple array with the classical hatch method (Fig.1. a). In this case, the processing speed is limited by the time for synchronization of the scanning system, especially, if the size of the dimples is below $100 \mu \mathrm{m}$. The position of the mirrors should be correlated with a high precision and for such small objects this becomes a difficult task [33]. The inertia of the mirrors does not give the possibility to correct the galvanometer scanner immediately. At higher speeds this limitation becomes obvious from the physical principles of the mechanical scanning systems [34]. For large textured fields, which contain millions of microobjects, this synchronization time can take minutes or tens of minutes. Moreover, a significant amount of data about the exact position of every microobject slows the computer processing, especially when the quantity of microobjects becomes higher than $10^{4}$ pcs.

A faster solution can be derived from the equidistant position of equal objects in LST. This gives a possibility to apply indirect control for the laser object formation at the highest speed of the scanning system. In this way, laser beam scanning is achieved by continual movement of the scanning mirrors without interruption of laser pulses generation at a constant repetition frequency. The passing out of allowed laser pulses is provided by a fast shutter independent of the inline mirror position (Fig.1. b). This independent shutter is based on a Pocket Cell with switching speed up to $20 \mathrm{~ns}$ and frequency up to $100 \mathrm{kHz}$ [35]. Such a highswitching speed of the shutter forms strongly defined ends of the segments with laser spots on the processed surface. For commonly used precise galvanoscanners with scanning speed of $8 \mathrm{~m} / \mathrm{s}$, the tolerance in the length of the segments will be around $0.1 \mu \mathrm{m}$.

Unlike in the pulse on demand solution (PoD), in the solution presented here the shutter works asynchronously with the laser generator and mirrors positions. This means that the position, length and distance between passed segments with laser spots is controlled entirely by the switching of the shutter. No laser pulse will be applied on the scanned surface in the areas, which correspond to the closed state of the shutter. The laser pulses will be only inside the allowed segments. For laser pulse generation in the $\mathrm{MHz}$ range, the laser pulses inside the scanned segments can have a microsecond delay. This means that the maximal jitter length for the mentioned scanning speed of $8 \mathrm{~m} / \mathrm{s}$ can reach up to $8 \mu \mathrm{m}$. But the mean value of the laser pulse deviation in scanned segments ends will be near $4 \mu \mathrm{m}$. Such a limitation indicates a possible deviation of the segments length for the sLST strategy.

There are experimental studies where it was shown that such sequences of weak laser pulses with microsecond time separation work as bursts [36, 37]. Such a burst regime was presented as a more efficient method for steel surface processing and cleaning in comparison to a single pulse mode [38]. The application of such sequences of laser pulses with an asynchronous shutter is presented here as sLST scanning strategy in burst regime.

The length of the laser spot segments corresponds to the duration of the laser pulse burst. Overlapping of laser spots in these segments is easily controlled by the laser pulses generation frequency. Repeating the same dotted line through the whole scanning field leads to the formation of a linear raster with short bursts of laser spots [39].
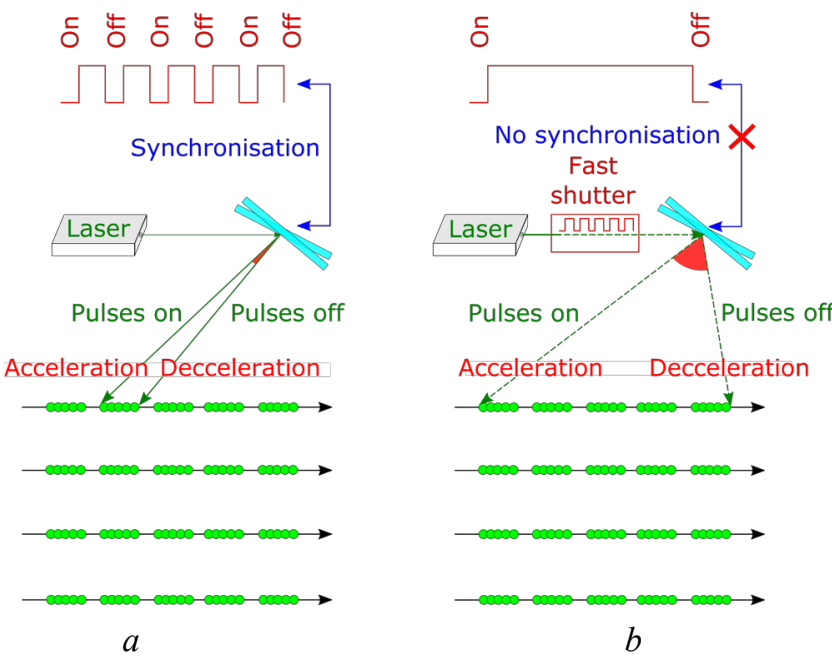

Fig. 1 Equidistant straight segments formed by: $a$ - classical hatch strategy. It is necessary to control the mirror position and laser switching for every object in the array; $b-$ shifted LST in burst regime. No need to know the position of every object. Synchronisation between laser and mirror position is provided only at the start and finish positions on the scanning field.

The shifted LST strategy for formation of microobjects with known geometry is based on short movement (shift) of the whole raster and consequential writing of the raster (Fig. 2. a). In the case of the nonrectangular form of the microobjects, different rasters contain bursts with different lengths (Fig. 2. b). In one raster, the burst length is constant The different length of the bursts is easily controlled by different duration of the switched-on state of the external trigger for every raster. Such a strategy for the formation of an array of microobjects is called sLST in burst regime. One important benefit of this strategy is the continual movement of the scanning mirror. There is no need to break or accelerate the mirror movement before and after the writing of every microobject in the texture. The mirrors inertia becomes a useful factor and surface texturing at the highest speeds should have better precision.

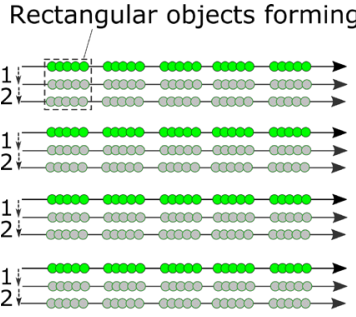

$a$

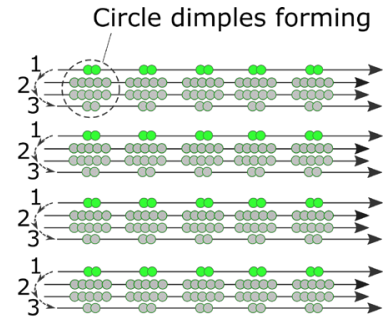

$b$
Fig. 2 Shifted strategy for formation of microobjects (sLST) in burst regime (short movement of the rasters is shown by dotted arrows): $a$ - with rectangular microobjects. Length of the bursts is the same for all rasters; $b$ - with circular microobjects. Length of the bursts is different in 
different rasters and controlled by duration of the switchedon state of the external trigger.

Another feature of the SLST is the significant reduction of the synchronization data transfer between the scanning system and the laser. In this case, only the starting and ending positions of the whole line in the raster need to be known. This means that the position of every object in the textured field is not controlled directly, only by mirror speed and external trigger frequency.

Material processing using the sLST strategy in burst regime has one more important benefit. Since this strategy is more applicable at higher speeds, it is possible to control the heat accumulation at a higher frequency of the laser generator. This factor allows the possibility to aiming highquality ablation in ultra-short pulsed laser material processing [13].

The benefits were verified experimentally in this study using a developed technique using high-emissivity paint on the textured surface. Details of the experimental setup and methods are described in the next section. Some real applications of the sLST strategy in burst regime are presented in later section on tungsten surface processing.

\section{Experimental setup and methods}

For experiments, a PX25-2-G solid-state laser with Innoslab technology (EdgeWave $\mathrm{GmbH}$ ) was used. This laser has wavelength $532 \mathrm{~nm}$, pulse duration $10 \mathrm{ps,} \mathrm{average}$ power $12 \mathrm{~W}$, maximum pulse energy $100 \mu \mathrm{J}$ and beam quality $\mathrm{M}^{2}<1.1$. The frequency of the laser generator used was in the range $140 \mathrm{kHz} \div 1.2 \mathrm{MHz}$ and the pulse energy used was $10 \div 12 \mu \mathrm{J}$. A full laser data sheet can be found in [40]. Scanning of the laser beam was provided by an intelliSCAN III 14 scan head (SCANLAB GmbH) [41]. Laser beam focusing was provided with an F-Theta objective with $255 \mathrm{~mm}$ focal length. This combination gives a maximal laser beam scanning speed equal to $8 \mathrm{~m} / \mathrm{s}$.

Stainless steel (AISI 304) plate samples were covered by high-emissivity LabIR ${ }^{\circledR}$ paint (Fig. 3) [42]. The samples were painted all together at once to ensure equal paint thickness. The thickness of the paint was $8 \div 10 \mu \mathrm{m}$. Laser processed paint-covered surfaces were analyzed with a Hirox 3D microscope (KH-7700). One laser pulse application with the mentioned pulse energy corresponds to paint removal with a diameter equal to $20 \mu \mathrm{m}$ (effective spot size). The full texture produced was analyzed using a contact surface profiler (KLA-Tencor P-6 Profiler) in parallel lines.

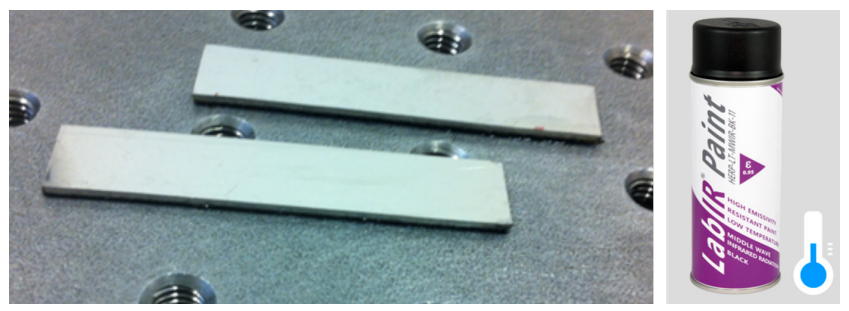

Fig. 3 Preparation of a surface for detection of the precision of a laser-scanning strategy: $a$ - source stainless steel samples; $b$ - low-temperature high-emissivity LabIR ${ }^{\circledR}$ paint [42].
The goal texture of the experiment contained equidistant dimples with $80 \mu \mathrm{m}$ diameter. Deviation of the object diameter from the goal size was detected by analyses of black and white images of the textured surfaces. Spot overlapping along raster lines was set equal to $7 \mu \mathrm{m}$. Line distance between the next rasters was set equal to $10 \mu \mathrm{m}$.

Images of textured surfaces taken by the optical microscope were analyzed with MATLAB Image Processing Toolbox based on morphological reconstruction [43]. For every scanning speed, more than 30 produced dimples were analyzed from three different places on the sample. In this way, the deviation between the diameter of the lasertextured objects (dimples) and their goal diameter was detected. Since the laser-textured objects have a slightly ellipsoidal form, both smaller and larger diameters were used for deviation analysis - in major and minor axes of a fitted ellipse (Fig. 4. a).

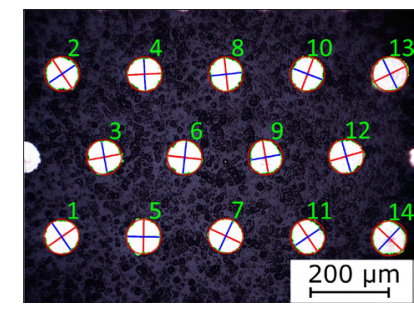

$a$

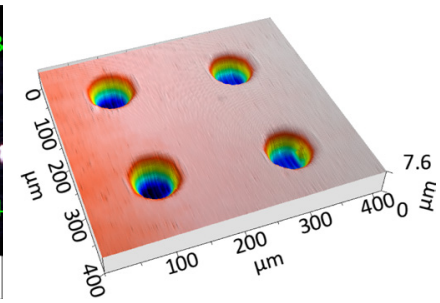

$b$
Fig. 4 Morphological analyses of laser-textured surface: $a$ - with LabIR $^{\circledR}$ paint and one scanning layer. Major axes of microobjects are red lines. Minor axes are blue lines; $b-$ $3 \mathrm{D}$ profile after 90 scanning layers.

Evaluation of the influence of heat accumulation on output roughness was provided by continuous laser processing of the sample areas $10 \times 2 \mathrm{~mm}^{2}$. It was done without interruption of the laser pulse generation and without application of the shutter. In this case microtexturing is not formed, but the roughness was evaluated on the wider laser-processed area. Comparison of the surface roughness obtained by using different scanning speeds and laser powers gives the possibility to determine the influence of bigger and smaller heat accumulation. These experiments were performed at a fixed laser frequency equal to $1143 \mathrm{kHz}$ and different scanning speeds and laser pulse energies. Maximal heat accumulation was achieved by slowly scanning the material with a speed of laser beam $0.2 \mathrm{~m} / \mathrm{s}$ and laser pulses energy equal to $11 \mu \mathrm{J}$. The influence of weak heat accumulation on the output roughness value was analyzed at maximal scanning speed and pulse energy equal to $2 \mu \mathrm{J}$. For different parameters of laser beam surface scanning, the count of scanning repetitions was determined by its variation to reach the texture depth of $6.5 \mu \mathrm{m}$.

\section{Results and Discussion}

The sequence of experiments using sLST in burst regime with different scanning speeds is presented in Table 1. In this table, it can be seen that the biggest deviation from the goal size of dimples was detected at minimal scanning speed. It is the same for the standard deviation and can be explained by the more stable mirror movement at higher speeds of texturing. 
Table 1 Dimple size deviation of sLST in burst regime for goal texture with $80 \mu \mathrm{m}$ dimple diameter.

\begin{tabular}{cccc}
\hline $\begin{array}{c}\text { Speed } \\
(\mathrm{m} / \mathrm{s})\end{array}$ & $\begin{array}{c}\text { Frequency } \\
(\mathrm{kHz})\end{array}$ & $\begin{array}{c}\text { Diameter } \\
\text { deviation }(\mu \mathrm{m})\end{array}$ & $\begin{array}{c}\text { Standard } \\
\text { deviation }(\mu \mathrm{m})\end{array}$ \\
\hline 1 & 142 & 5.44 & 2.78 \\
1.5 & 214 & 2.93 & 2.10 \\
2 & 286 & 2.16 & 1.36 \\
3 & 429 & 2.72 & 1.56 \\
4 & 571 & 3.19 & 2.07 \\
5 & 714 & 2.88 & 2.16 \\
6 & 857 & 2.64 & 1.77 \\
7 & 1000 & 2.14 & 1.34 \\
8 & 1143 & 3.05 & 2.02 \\
\hline
\end{tabular}

The processing time for SLST in burst regime takes 1.9 seconds for 10,000 objects being written in one scanning layer. This corresponds to a surface processing speed of more than $1.3 \cdot 10^{3} \mathrm{~mm}^{2}$ per minute. This is more than 45 times faster than the analogous classical hatch scanning strategy with the same precision.

High-speed surface texturing using sLST can be applicable for industrial applications in different fields. Especially, if the material should be processed at a specific temperature regime with the aim of minimal roughness of surface. In our experiment, the roughness of the laserprocessed materials was measured inside the dimples with a contact surface profiler on textured samples without paint. The samples were laser processed till the dimple depth reached $6.5 \mu \mathrm{m}$ (Fig.4. b). Measured minimal roughness on the bottom of these dimples produced by the sLST in burst regime was $R_{a}=0.03 \mu \mathrm{m}$.

The combination of laser frequency with high scanning speed initiates optimal thermomechanical fields for achieving high processing quality with a smooth surface. The minimal roughness of $R_{a} \approx 0.17 \mu \mathrm{m}$ was achieved at a maximal scanning speed of $8 \mathrm{~m} / \mathrm{s}$ and pulse energy $11 \mu \mathrm{J}$. This regime of laser machining can be said to be a positive heat accumulation in burst regime. For the maximal heat accumulation at the slow speed of $0.2 \mathrm{~m} / \mathrm{s}$, the measured roughness was $R_{a} \approx 1 \mu \mathrm{m}$. The minimal heat accumulation was achieved at a maximal scanning speed of $8 \mathrm{~m} / \mathrm{s}$ and minimal laser pulse energy $2 \mu \mathrm{J}$. In this case, the measured roughness was equal to $R_{a} \approx 0.5 \mu \mathrm{m}$. A noteworthy detail is that this value of roughness $0.5 \mu \mathrm{m}$ was detected for the same scanning speed and overlapping as in the experiment with minimal output roughness $0.17 \mu \mathrm{m}$. Only pulse energy, and, as a result, heat accumulation were smaller. Additionally, for such lower energy of the laser pulse, nearly ten times more scanning repetitions should be applied for achieving the same depth. In the next section, some physical principles of achieving positive heat accumulation will be discussed.

\section{Positive heat accumulation}

There are a lot of literature sources showing that a smooth, low-roughness surface can be achieved at the max- imal possible scanning speed [12]. When the temperature of the scanned surface rises close to melting point, heat accumulation in laser machining is described as an undesirable effect [13]. However, in some works it was pointed out, that low-heat accumulation has a positive role for achieved higher process quality [44-46]. Positive heat accumulation is defined here as a temperature regime of laser material processing where the laser-processed surface has lower roughness than in other regimes. Such positive heat accumulation can be achieved with laser ablation different or even much smaller than the maximal possible ablation rate. In this study, we have theoretically evaluated the heat accumulation in stainless steel plate under the laser-scanning line. For a subsurface fixed point, the heat accumulation can be defined from a simplified semi-planar model of pulsed scanned source [46]:

$$
\Delta T_{\text {Sum }}(t, z)=(\rho \cdot c \cdot \sqrt{\pi \cdot \alpha})^{-1} \cdot \sum_{n=1}^{N} F_{n} \cdot e^{-\frac{z^{2}}{4 \cdot \alpha \cdot\left(t-t_{n}\right)}} / \sqrt{t-t_{n}}
$$

where $\Delta T_{\text {Sum }}$ is accumulated temperature, $t$ - time from the start of the laser-scanning process across the fixed point, $z$ - depth position of the subsurface fixed point, $n$ - the number of laser pulses applied over the fixed point, $F_{n}$ laser fluence at moment $t_{n}$ on the surface, $\rho$ - material density, $c$ - specific heat, $\alpha$ - thermal diffusivity, $N$ - full number of the laser pulses over the fixed point, which were applied till actual time $t$ and $t_{n}$ - time when the laser pulse with index $n$ is applied. In this model, the scanning speed was included in the calculation of the laser fluence $F_{n}$, because it will be different for every next laser pulse on the fixed surface point.

$F_{n}$ can be defined from Gaussian light distribution at one laser spot and scanning speed using equation [47]:

$F_{n}=\eta \cdot F_{0} \cdot e^{-2 \cdot\left(n \cdot v / f \cdot \omega_{0}\right)^{2}}$

where $F_{n}$ is laser fluence at moment $t_{n}$ at the fixed point on the scanned surface, $\eta$ - fraction coefficient of absorption, $F_{0}$ - laser fluence in the center of the laser spot, $v$ laser beam scanning speed, $f$ - repetition frequency of laser source and $\omega_{0}$ - beam half-width. Here the equation $n \cdot v / f$ describes the distance between the center of the laser spot with index $n$ and the fixed point on the scanned surface. In this model, the laser spot is considered as an array of discrete heat sources $F_{n}$ with a small temperature gradient between neighboring points [48, 49]. This is true for burst regime, when the short period between laser pulses is not long enough for cooling down of the scanned surface.

Similar model for determination of heat accumulation was applied by Bauer [12] for a scanning laser beam. This model is commonly used for evaluation of temperature changes in a moving surface point, corresponding to the center of each laser spot in the scanning line [12, 13]. In the calculations presented here, heat accumulation was evaluated in a different way. The temperature changes were analyzed only for one fixed surface point, over which the 
laser beam is scanned. This means that each laser pulse is applied at a different distance from the analyzed fixed surface point. The absorbed energy in the fixed surface point will be different for each laser pulse, according to Gaussian distribution of fluence (Eq. 2).

Parameters of the laser process used in the calculation were similar to the experimental setup: energy in the laser pulse $11 \mu \mathrm{J}$, effective laser spot diameter $20 \mu \mathrm{m}$ and laser repetition frequency $1143 \mathrm{kHz}$. The fraction coefficient in Eq. 2 was taken equal to $12,5 \%$, as in [13]. This fraction coefficient describes the whole residual heat energy after laser pulse application - the direct laser energy absorption and secondary heat transfer, for example, from a plasma plume or hot vapors. It is the only free (fitting) parameter for evaluation of the relative temperature changes in laserscanned subsurface layers. For the calculations, temperature dependencies of thermal and mechanical properties of stainless steel AISI304 (from MPDB [50]) were applied. Minimal geometry discretization steps were set at $\Delta x, \Delta y, \Delta z=0.5 \mu \mathrm{m}$ and the time step was equal to $\Delta t=0.1 \mathrm{~ns}$.

Heat accumulation was defined for SLST in burst regime for points fixed on the scanned surface and under it in depth down to $5 \mu \mathrm{m}$. Calculations were done for maximal possible scanning speed $(8 \mathrm{~m} / \mathrm{s}$ for our experimental conditions). The inline spot distance $7 \mu \mathrm{m}$ at this speed corresponds to $0.875 \mu \mathrm{s}$ delay between laser pulses. This time is short enough for the application of the mentioned semiplanar model of heat distribution. Results of the calculation are shown in Fig. 5, where the maximum temperature on this graph was limited by the melting point of the sample material. The values in the legend mean depths under the fixed surface point. Since the laser beam is scanned on the surface across this point, the temperature increased at the start and then, after a direct hit, slowly decreased, longer than $10 \mu \mathrm{s}$. On the surface $(z=0 \mu \mathrm{m})$, the heat accumulation value is rises to $\Delta T_{\text {Sum }}(4.25 \mu \mathrm{s}, 0 \mu \mathrm{m}) \approx 350 \mathrm{~K}$. Nearly the same value is obtained for the next subsurface point $(z=1 \mu \mathrm{m}) \Delta T_{\text {Sum }}(4.27 \mu \mathrm{s}, 1 \mu \mathrm{m}) \approx 330 \mathrm{~K}$.

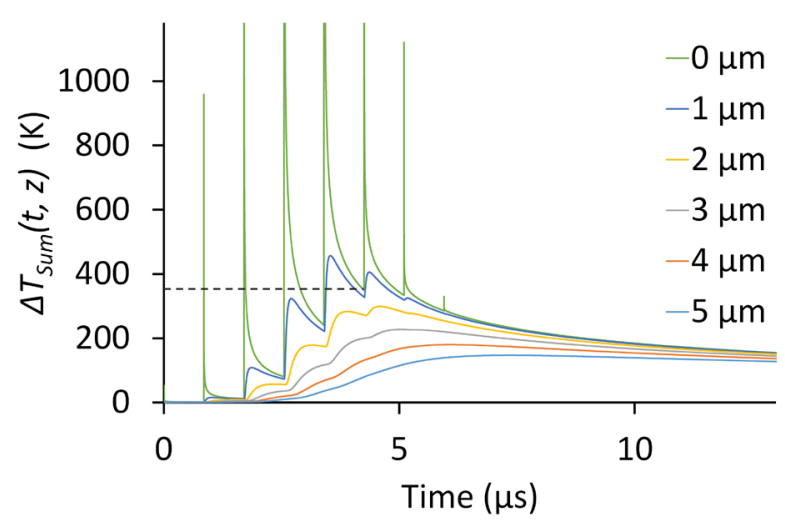

Fig. 5 Temperature changes on the surface and in subsurface layers of stainless steel plate in the fixed point under the laser-scanning beam. The dashed straight line corresponds to a maximal heat accumulation on the scanned surface. (Scanning speed 8m/s, laser frequency $1143 \mathrm{kHz}$, pulse energy $11 \mu \mathrm{J}$; different colored lines correspond to temperature at different depth)

The temperature gradient between these two depths is smaller than $20 \mathrm{~K} / \mu \mathrm{m}$. But this gradient becomes more than three times bigger for the next depth step and is around $60 \mathrm{~K} / \mu \mathrm{m}$. For this deeper layer at depth $2 \mu \mathrm{m}$, the heat accumulation is $\Delta T_{\text {Sum }}(7.69 \mu \mathrm{s}, 2 \mu \mathrm{m}) \approx 270 \mathrm{~K}$. The lower roughness of the laser-processed surface with such temperature distribution can be explained by the specific state of the scanned surface. Heat accumulation of $380 \div 360 \mathrm{~K}$ in the upper layers corresponds to a temperature region where the tensile strength of AISI304 becomes lower (Fig. 6) [51].

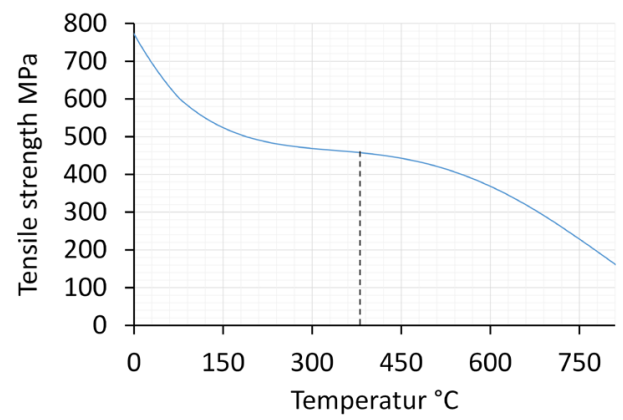

Fig. 6 Tensile strength of stainless steel AISI304 in dependence on temperature. The dashed straight line corresponds to maximal heat accumulation on the scanned surface

This preheating regime of laser material processing leads to softening of the upper layer of the sample material. In this way, the ablation processes, like spallation and phase explosion, will be more preferred in these thin preheated surface layers and less preferred for the deeper and cooler layers with higher strength. The accentuated temperature gradient between upper and deeper surface layers leads to smoother laser material removal and this can be described as exfoliation of the upper layers by laser ablation. This temperature field, which is achieved in burst regime, is presented as the optimal condition for achieving an output surface with low roughness.

Calculations for a slow scanning speed of $0.2 \mathrm{~m} / \mathrm{s}$ has shown that surface temperature reached higher values than the melting point $1455^{\circ} \mathrm{C}$. The appearance of the melting phase can initiate material flow and redeposition. This can explain the higher roughness of a slow-speed scanned laser surface with the formation of resolidified bumps [1, 12].

The opposite scanning strategy using maximal scanning speed $8 \mathrm{~m} / \mathrm{s}$ and minimal pulse energy $2 \mu \mathrm{J}$ produces only $60 \div 70^{\circ} \mathrm{K}$ of heat accumulation. In this case the increase of the roughness cannot be explained by melting deposition. Temperature changes are localized in a thin $1 \mu \mathrm{m}$ layer and the whole subsurface material stays at the initial temperature. In this case, the laser affected zone becomes very sensitive for precursor states and cones formation can appear [44, 52, 53]. 


\section{Application of sLST in burst regime}

The strategy of sLST in burst regime presented in this article was applied to machining of different materials. As mentioned before, this strategy gives the possibility to provide texturing of a material surface at high speed and high precision. One of the last applications of sLST was the microtexturing of tungsten substrate for plasma spraying. The basic demand was the exact size of microobjects and the flat bottom of the laser-scanned surface. Two unusual textures produced by SLST in burst regime are presented here: circular columns and donut structures. In the first step, the optimal combination of laser parameters for achieving a smooth, low-roughness surface at maximal scanning speed was found. In the second step, external trigger delays were configured for the collection of rasters and formation of microobjects (see Fig. 1.b and Fig. 2). The resulting textures, measured by scanning electron microscopy (SEM), are presented in Fig. 7.
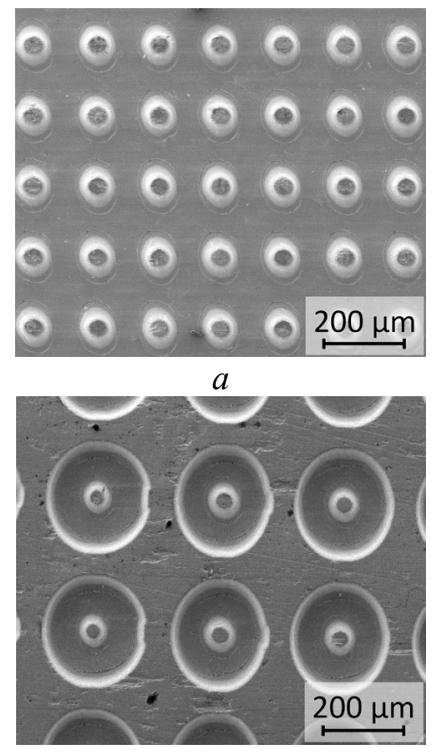

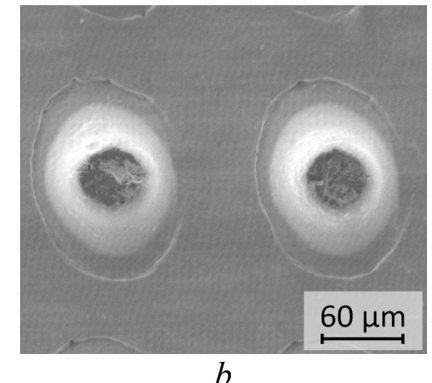

$d$

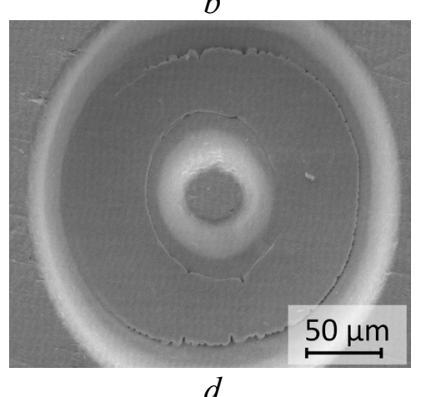

Fig. 7 SEM images of a tungsten surface after SLST in burst regime: $a$-structure with $80 \mu \mathrm{m}$ height columns; $b-$ magnification of the same columns; $c$ - structure with $80 \mu \mathrm{m}$ depth donuts; $d$-magnification of the same donut structure. (Laser beam scanning speed $8 \mathrm{~m} / \mathrm{s}$, frequency $1010 \mathrm{kHz}$ and pulse energy $12 \mu \mathrm{J}$.)

\section{Conclusion}

A new method of laser surface texturing was developed. It is called shifted LST in burst regime. It has a great potential for high-speed precision material processing. Unlike the classical line-by-line hatching, the sLST strategy works asynchronously from position of mirrors with stable generation of the laser bursts and independent continuous movement of the mirrors. In this paper, several examples of the application of this strategy were described.

A new methodology was developed for evaluation of the precision of laser texturing. High-emissivity LabIR ${ }^{\circledR}$ paint ablation with Matlab analysis of high-contrast images can be applied as a standard method for precision evaluation of any laser-scanning strategies. In this way, it was found that the deviation of microobjects' size is smaller than $4 \mu \mathrm{m}$ for the maximal scanning speed of sLST.
The precision of the shifted method processing does not depend on the scanning speed. Therefore, the shifted method is assumed to work at significantly higher scanning speeds (using, for example, a polygon scanner) with the same precision and to achieve significantly higher processing speeds.

Positive heat accumulation was discussed from a thermomechanical point of view as a softening factor for subsurface material layers. Exfoliation of the upper layers of the laser-processed material is considered a result of higher temperature gradients between the upper and bottom layers of the laser-scanned material.

\section{Acknowledgments}

The work was supported by the Ministry of Education, Youth and Sports of the Czech Republic (OP RDI programme, CENTEM project, no. CZ.1.05/2.1.00/03.0088, co-funded by the ERDF; NPU I programme, CENTEM PLUS project no. LO1402); and project SGS-2019-008.

\section{References}

[1] N. Bulgakova, A. Panchenko, V. Zhukov, S. Kudryashov, A. Pereira, W. Marine, T. Mocek, and A. Bulgakov: Micromachines, 5, (2014) 1344.

[2] J. Ion: "Laser Processing of Engineering Materials: Principles, Procedure and Industrial Application" (Elsevier, Oxford, 2005) p.576.

[3] B. Liu, W. Wang, G. Jiang, X. Mei, K. Wang, and J. Wang: J. Nanomater., 2013, (2013) 1.

[4] G. Tani, L. Orazi, A. Fortunato, A. Ascari, and G. Campana: CIRP Ann., 60, (2011) 219.

[5] B. Wu, S. Tao, and S. Lei: Appl. Surf. Sci., 256, (2010) 4376.

[6] U. Loeschner, J. Schille, A. Streek, T. Knebel, L. Hartwig, R. Hillmann, and C. Endisch: J. Laser Appl., 27, (2015) S29303.

[7] J. Lopez, R. Kling, R. Torres, A. Lidolff, M. Delaigue, S. Ricaud, C. Hönninger, and E. Mottay: 12th International Symposium on Laser Precision Microfabrication, (2012) p. 82430O.

[8] J. Schille, L. Schneider, A. Streek, S. Kloetzer, and U. Loeschner: Proc. SPIE, 9736, (2016) p. 97360R.

[9] G. Raciukaitis, M. Brikas, P. Gecys, and M. Gedvilas: Proc. SPIE, 7005, (2008) p. 70052L.

[10] F. Di Niso, C. Gaudiuso, T. Sibillano, F. P. Mezzapesa, A. Ancona, and P. M. Lugarà: Opt. Express, 22, (2014) 12200.

[11] N. Farid, S. S. Harilal, H. Ding, and A. Hassanein: Appl. Phys. Lett., 103, (2013) 191112.

[12] F. Bauer, A. Michalowski, T. Kiedrowski, and S. Nolte: Opt. Express, 23, (2015) 1035.

[13] R. Weber, T. Graf, P. Berger, V. Onuseit, M. Wiedenmann, C. Freitag, and A. Feuer: Opt. Express, 22, (2014) 11312.

[14] T. Häfner, J. Heberle, M. Dobler, and M. Schmidt: J. Laser Appl., 28, (2016) 022605.

[15] F. Bauer, A. Michalowski, T. Kiedrowski, and S. Nolte: Opt. Express, 23, (2015) 1035.

[16] A. Ancona, F. Röser, K. Rademaker, J. Limpert, S. Nolte, and A. Tünnermann: Opt. Express, 16, (2008) 8958. 
[17] T. Kramer: J. Laser Micro/Nanoengineering, 12, (2017) 107.

[18] S. Bruening, G. Hennig, S. Eifel, and A. Gillner: Phys. Procedia, 12, (2011) 105.

[19] D. Moskal, M. Kučera, E. Smazalová, S. Houdková, and R. Kromer: METAL 2015 - 24th International Conference on Metallurgy and Materials, Brno, (2015) p. 4103.

[20] G. R. B. E. Römer and P. Bechtold: Phys. Procedia, 56, (2014) 29.

[21] P. Šugár, J. Šugárová, and M. Frnčík: Open Eng., 6, (2016) 90.

[22] B. Neuenschwander, B. Jaeggi, M. Zimmermann, V. Markovic, B. Resan, K. Weingarten, R. de Loor, and L. Penning: International Congress on Applications of Lasers \& Electro-Optics (ICALEO), Atlanta, (2015) p. 14.

[23] R. De Loor: Phys. Procedia, 41, (2013) 544.

[24] K. Du: DE20161005421 20160508 (2018).

[25] Š. Houdková, P. Šperka, M. Repka, J. Martan, and D. Moskal: J. Phys. Conf. Ser., 843, (2017) 012076.

[26] M. Geiger, S. Roth, and W. Becker: Surf. Coatings Technol., 100-101, (1998) 17.

[27] D. Patel, V. Jain, and J. Ramkumar: Proc. Inst. Mech. Eng. Part B J. Eng. Manuf., 232, (2018) 941.

[28] B. Zheng, W. Wang, G. Jiang, and X. Mei: Appl. Phys. B, 122, (2016) 180.

[29] K. Sugioka: Nanophotonics, 6, (2017) 393.

[30] L. Li, W. Guo, Z. B. Wang, Z. Liu, D. Whitehead, and B. Luk'yanchuk: J. Micromechanics Microengineering, 19, (2009) 054002.

[31] R. Kromer, S. Costil, J. Cormier, D. Courapied, L. Berthe, P. Peyre, and M. Boustie: Surf. Coatings Technol., 278, (2015) 171.

[32] L. Yang, H. Gong, S. Dilip, and B. Stucker: Solid Freeform Fabrication, (2014) p. 714.

[33] M. Zimmermann, B. Jaeggi, and B. Neuenschwander: Laser Applications in Microelectronic and Optoelectronic Manufacturing (Lamom) XX, San Francisco, (2015) p. 935016.

[34] J. Martan, D. Moskal, and M. Kučera: J. Laser Appl., 31, (2019) 022507.

[35] Q. B. Du Keming, Li Daijung: DE Patent 102014017568 B4 (2016).

[36] C. Meinhardt, V. Sturm, R. Fleige, C. FrickeBegemann, and R. Noll: Spectrochim. Acta Part B At. Spectrosc., 123, (2016) 171.

[37] L. M. Cabalín, A. González, V. Lazic, and J.
Laserna: Appl. Spectrosc., 65, (2011) 797.

[38] A. Löbe, J. Vrenegor, R. Fleige, V. Sturm, and R. Noll: Anal. Bioanal. Chem., 385, (2006) 326.

[39] D. Moskal, J. Martan, and M. Kučera: LIM2017, Munich, (2017).

[40] EdgeWave GmbH: Datasheet. [Online]. Available: https://www.edge-wave.de/web/wpcontent/uploads/2018/03/PXweb2018.pdf. [Accessed: 21-Jun-2018].

[41] SCANLAB: Datasheet. [Online]. Available: http://www.scanlab.de/sites/default/files/PDFDateien/Data-Sheets/Scan-Systems/intelliSCANEN.pdf. [Accessed: 21-Jun-2018].

[42] West Bohemia University in Plzen: Thermographic paint for standard applications, (2018). [Online]. Available: http://paints.labir.eu/documents/LabIR Paint HERP-LT-en-product leafleft-web.pdf. [Accessed: 21-Jun-2018].

[43] P. Soille: "Morphological Image Analysis" (Springer Berlin Heidelberg, Berlin, Heidelberg, 2004) p.391.

[44] D. Moskal, J. Martan, E. Smazalová, and Š. Houdková: METAL 2016 - 25th Anniversary International Conference on Metallurgy and Materials, Brno, (2016).

[45] H. Sobral and R. Sanginés: Spectrochim. Acta Part B At. Spectrosc., 94-95, (2014) 1.

[46] D. Moskal, J. Martan, M. Kučera, Š. Houdková, and R. Kromer: Phys. Procedia, 83, (2016) 249.

[47] E. Hecht: "Optics" ed. by A. Black (AddisonWesley, San Francisco, 2002) p.698.

[48] N. Rykalin: "Rascety teplovych processov pri svarke" ed. by A. Jerohin (MASGIZ, Moscow, 1951) p.296.

[49] H. S. Carslaw and J. Jaeger: "Conduction of heat in solids" (Oxford at the Clarendon Press, 1959) p.510.

[50] I. JAHM Software: [Online]. Available: https://www.jahm.com. [Accessed: 22-Oct-2018].

[51] ATI: Datasheet, (2018). [Online]. Available: https://www.atimetals.com/Products/ati-304.

[52] C. A. Zuhlke, T. P. Anderson, and D. R. Alexander: Opt. Express, 21, (2013) 8460.

[53] E. J. Y. Ling, J. Saïd, N. Brodusch, R. Gauvin, P. Servio, and A.-M. Kietzig: Appl. Surf. Sci., 353, (2015) 512.

(Received: June 23, 2018, Accepted: May 20, 2019) 